\title{
The discipline of tracing in architectural drawing
}

\section{Document Version}

Accepted author manuscript

Link to publication record in Manchester Research Explorer

\section{Citation for published version (APA):}

Lucas, R. (2017). The discipline of tracing in architectural drawing. In C. Johannessen, \& T. Van Leeuwen (Eds.), The Materiality of Writing: A Trace Making Perspective (pp. 116-137). (Routledge Studies in Multimodality). Routledge.

\section{Published in:}

The Materiality of Writing

\section{Citing this paper}

Please note that where the full-text provided on Manchester Research Explorer is the Author Accepted Manuscript or Proof version this may differ from the final Published version. If citing, it is advised that you check and use the publisher's definitive version.

\section{General rights}

Copyright and moral rights for the publications made accessible in the Research Explorer are retained by the authors and/or other copyright owners and it is a condition of accessing publications that users recognise and abide by the legal requirements associated with these rights.

\section{Takedown policy}

If you believe that this document breaches copyright please refer to the University of Manchester's Takedown Procedures [http://man.ac.uk/04Y6Bo] or contact uml.scholarlycommunications@manchester.ac.uk providing relevant details, so we can investigate your claim.

\section{OPEN ACCESS}




\title{
The Discipline of Tracing in Architectural Drawing
}

\author{
Dr Ray Lucas, \\ University of Manchester, \\ Manchester School of Architecture
}

\author{
INTRODUCTION
}

This paper considers the nature of tracing ${ }^{1}$ in architecture, a fundamental drawing practice which relies upon transparent paper, allowing lines from one drawing to be selectively re-used in subsequent inscriptions. Whilst not unique to architecture, tracing paper found prominence in the discipline and embedded itself as a key technology within the design process. The use of tracing paper is replicated by contemporary CAD software, where layers mimic stacks of translucent paper and allow copying, iterative designs, and cross-referencing of alternative projections. Tracing is under-theorised within the body of literature on architectural drawing. This is due in part to the focus on lines and marks which constitute drawing, and insufficient attention paid to the support, most often paper, upon which the marks are made. Drawing can be said to consist of the contact between mark and surface, however, and by ignoring the support we are missing a large part of the story.

Writing at the turn of the 15th Century, the Florentine artist Cennino d'Andrea Cennini described many practices and processes of Renaissance art. One such process was the production and uses of tracing paper:

\begin{abstract}
'You should be aware that there is also a paper known as tracing paper which may be very useful to you. To copy a head, or a figure, or a half figure, as you may find it attractive, by the hand of the great masters, and to get the outlines right, from paper, panel, or wall, which you want to take right off, put this tracing paper over the figure or drawing, fastening it nicely at the four corners with a little red or green wax. Because of the transparency of the tracing paper, the figure or drawing underneath immediately shows through, in such shape and manner that you see it clearly. Then take either a pen cut quite fine or a fine brush of fine miniver; and you may proceed to pick out with ink the outlines and accents of the drawing underneath' and in general to touch in shadows as far as you can see to do it. And then, lifting off the paper, you may touch it up with any high lights and reliefs, as you please.' (1960:13)
\end{abstract}

This is accompanied by a detailed account of how to make tracing paper (through various processes such as scraping or applying glues \& oil) and parchment, but it is notable that this brief discussion of tracing paper moves quickly from replicating the work of a master towards some interpretative or additional intervention in the production of the drawing. The original is grounds for invention rather than something to be blindly reproduced.

The discussion of tracing paper sits alongside the utility of copying from the great masters and from nature; drawing from nature seen as a form of copying rather than representation in this context. The guiding hand of the master draughtsman underpins this process: the use of a drawing to guide and direct the learning of another artist directly.

\footnotetext{
1 The use of tracing denotes, throughout this paper, the act of drawing with or on tracing paper or other similar transparent papers. The concept of trace is distinctive from this, used by writers including Ingold do discuss the relationship between mark-making and movement, the mark being a trace left by a gesture. This distinction is maintained throughout.
} 
'But I give you this advice: take care to select the best one every time, and the one who has the greatest reputation. And, as you go on from day to day, it will be against nature if you do not get some grasp of his style and of his spirit. For if you undertake to copy after one master today and after another tomorrow, you will not acquire the style of either one or the other, and you will inevitably, through enthusiasm, become capricious, because each style will be distracting your mind.' (1960:15)

Outside of this context, tracing paper found continued utility in the production of architectural designs, with the increasing professionalisation of the discipline relying on both the ability to reproduce designs from antiquity and to iterate within the design process itself, making modifications one layer after another.

\section{TRACED DRAWINGS AS KNOWLEDGE PRODUCTION}

Architectural academic Stanford Anderson, in his paper Architectural Design as a System of Research Programs, establishes the research basis of architecture in the conventional methods of design. He writes of this research as an imperfect method: every bit as imperfect as we might assume ethnographic research, experimental investigations, and critical discourse analysis as similarly imperfect but still valid forms of research.

'In every field, our knowledge is imperfect, is not open to ultimate verification, is the product of a particular history. Our knowledge and other cultural forms might have been otherwise, and to that extent we recognise their conventionality-that they are, to a degree, arbitrary. But it is arbitrariness to a degree. Who is to say whether the medicine of the west or the cognate practices of China has set out on a better course? Yet it is clear that both systems, marked\} by some arbitrariness of beginning and course, have improved themselves because their respective conventions eventually encounter empirical problems which challenge them and channel further inquiry.' Anderson, S. 1984. in Hays, K. M. (Ed.). 2000:492.

Whilst the specific meaning of convention here is the more commonplace usage, convention, in terms of a set of rules governing the production and reception of a drawing is important to the discussion of architectural drawing, referring to different modes of representation including plan, section and elevation. Anderson uses an established description of research from the philosophy of science and mathematics, as described by Imre Lakatos (1978:10) in order to substantiate his claims for architectural knowledge production (aka research) through design. The differentiation is cleverly drawn, however, and Anderson uses Lakatos' notion of a 'nonmalleable hard core and an equally obdurate empirical reality' (2000:497) to underlines the idea that in architecture:

'the architect is involved in making his own reality as well as his theory' (2000:497)

This is similar to my assertion elsewhere (Lucas 2014:136) that architects provide context as well as working within an extant site. Sometimes architecture is provocative and open regarding programme or function.

If architecture can be said to be research, then the question of its methodologies becomes apparent: the use of specific understandings of a site and context, the use of drawings, physical models, and digital representations: all of these contribute to a habitus for doing or practicing architecture. This then begs several questions about what is involved in the design process, even the 'normative' process described by Anderson (before we begin to address alternative ideas of practice such as user-centred design, co-design, self-build, parametricism, or architectural competitions).

This paper focuses on one under-represented aspect of architectural drawing: tracing. 
Of course, tracing has its own history, and the art historian Victor Stoichita addresses the myth that tracing can be found in the roots of Western painting, as per the account by Pliny.

'As to the Greeks, some of them say it was discovered at Sicyon, others in Corinth, but all agree that it began with tracing an outline around a man's shadow and consequently that pictures were originally done in this way'

'Enough and more than enough has now been said about painting. It may be suitable to append to these remarks something about the plastic art. It was through the service of that same earth that modelling portraits from clay was first invented by Butades, a potter of Sicyon, at Corinth. He did this owing to his daughter, who was in love with a young man; and she, when he was going abroad, drew in outline on the wall the shadow of his face thrown by the lamp. Her father pressed clay on this and made a relief, which he hardened by exposure to fire with the rest of his pottery; and it is said that this likeness was preserved in the Shrine of the Nymphs.'

Pliny, Natural History, xxxv, 15 \& 43, cited in Stoichita, 1997:11.

This is a story which has long perplexed art historians, of course, and the myth includes elements which indicate the beginning of images, related to the weight given to this idea of the shadow in particular, and its relation to antique notions of the soul. By relating the origins of art to the tracing of a shadow, it embeds the idea of the direct copy in art from its origins in the west: that the gesture follows a prescribed path finds us discussing tracing once again.

Tracing is, then, a gesture of following: an established path gives guidance to the hand and eye.

The idea of a gesture is helpful here - and suggests that media theorist Vilém Flusser might be of some assistance. Writing on The Gesture of Painting (2014:65), he asserts the importance of the enigma and contrasts it with problems:

'In starting to decipher the gesture, to solve its enigma, it will become clear that there are various levels from which it is "legible" and that these levels can be ordered hierarchically. For example, there is the level with the meaning "brush stroke," one below this with the meaning "colour composition." The enigma of the gesture of painting can be resolved on various semantic levels, and each level produces another way of reading. The more levels the person analysing is able to distinguish, and the more successful he is in coordinating these levels, the richer the meaning of a gesture will be. That is a characteristic of the semantic method: it permits a phenomenon to unfold its meaning in the course of the analysis. Through analysis, it becomes denser. That is also what distinguishes semantic from causal analyses. One analyses problems to be able to see through them, and so to get them out of the way. Problems solved are no longer problems. One analyses enigmas to enter into them. Enigmas solved remain enigmas. The goal of an analysis of the gesture of painting is not to clear painting out of the way. Rather, it so sits of entering into the enigma of painting more deeply so as to be able to draw a richer experience from it.'

Contrast with his account of photographing (notably not photography) 2014:72:

'A photograph is a kind of "fingerprint" that the subject leaves on a surface, and not a depiction, as in painting. The subject is the cause of the photograph and the meaning of painting. The photographic revolution reverses the traditional relationship between a concrete phenomenon and our idea of the phenomenon. In painting, according to this tradition, we ourselves form an "idea" to fix the phenomenon on the surface. If photography, by contrast, the phenomenon itself generates it's own idea for us on the surface. In fact, the invention of photography is a delayed technical resolution of the theoretical conflict between the rationalist and empirical idealism.' 
This suggests that the gestures of drawing are manifold, and that the gesture of tracing is one important element of this. Tracing represents a form of copying which opens the original source up to intervention and interpretation: that the initial copying moves beyond replication. Tracing possesses some of the qualities of painting and of photography noted by Flusser above, it opens up an enigma rather than a problem, and it also produces a direct kind of print: every drawing becomes a score (a la Goodman) for further gestures, further inscriptions. We might begin to understand the gestures of tracing to be a combination of both modes: at times, akin to the enigma of painting when the possibilities present within the deep pile of paper are being mined, and at other times having more in common with the fingerprint of photography with the act of retracing and copying a particular line or form.

This gestural quality is described by Juhani Pallasmaa in terms of tactile responses and a unity of hand, eye, and mind:

'For the sportsman, craftsman, magician and artist alike, the seamless and unconscious collaboration of the eye, hand and mind is crucial. As the performance is gradually perfected, perception, action of the hand and throughout lose their independence and turn into a singular and subliminally coordinated system of reaction and response. Finally it is the maker's sense of self that seems to be performing the task as if his/her existential sense exuded the work, or performance.' Pallasmaa, 2009:82.

Whilst Pallasmaa describes sketching as 'a process of observation and expression, receiving and giving at the same time... a drawing looks simultaneously outwards and inwards' (2009:90-91), something of the process of tracing can be found: simultaneously addressing the 'original' drawing and the further possibilities it contains. Discussions of copying are essential to understand what is happening in this process.

Simply stated, the gesture of tracing involves a rehearsed set of movements: one retraces steps already taken, and engages this replication in either embedding the key moves, lines, and interventions: or editing, curating, eliding or ignoring the unwanted inscriptions. Tracing is a selection procedure which is distinctly manual in nature, it allows for repetition and serial production: variations on a theme might be produced for comparison.

Confidence in the original drawing is crucial: it's proportions and measurements must be known to be correct and true, such is the certitude of the language surrounding drawing that notions of truth in angles are unproblematic. This gives the basis for exploration. The original is interrogated and tested, often treated as a hypothesis in the conventional research sense of the word: many students and architects will report the cyclical nature of the traced drawing - that more often than not, the original drawing is returned to in some way. This indicates that the process is often one of verifying that initial response to the design parameters, testing it against the other possibilities, but that the essence of that original hunch holds. Design, then, is not the straight lines of ever marching progress in the Gantt chart, but consists of loops and knots, of progress and return, of erasure and copying.

\section{COPYING \& INNOVATION}

Discussion of copying features strongly in Mario Carpo's recent work on architectural drawing The Alphabet and the Algorithm. Here, the discussion is of identicality, and how it is ingrained in architectural thought in the West since Alberti. The main aim of the work is to draw comparisons between early forms of the transmission of architectural instruction with contemporary, digital forms: noting that the digital isn't quite the paradigm shift that it is made out to be. Carpo cites several examples of algorithmic architecture, particularly related to the communication, transmission, and copying of drawings dating back to the Renaissance, and presents digital representation as something which might have become more efficient, but is not fundamentally new. Carpo makes explicit reference throughout to Nelson Goodman's work on notation as a description of architectural design practices. His argument that Architecture lies in the design much more than the building is interesting and echoes 
Unwin's assertion that one is better off drawing than visiting an important building: the kind of understanding gained being intrinsically architectonic and spatial.

The reproduction angle which he explores is particularly interesting, and gives the notion of the copy a great deal more nuance and historical context than we might at first imagine, and sees the current trends for parametric design to be very clearly prefigured in both medieval and Renaissance practices of design and building.

'The fact that in most cases the architect's design should beget only one building (and not a series of copies, as would a printing press, or a late medieval scriptorium) is irrelevant in this context, what matters is the relation of identical it's between the original and its reproduction. Alberti's entire architectural theory is predicated on the notational sameness between design and building, implying that drawings can, and must, be identically translated into three-dimensional objects. In Alberti's theory, the design of a building is the original, and the building is its copy.' Carpo, 2011:26

Later, Carpo investigates the places where this has been overturned or even reversed: he does not simply subscribe to Alberti's theories, aware of their context and utility. He does find, however, in Alberti's Descriptio urbis Romae, the roots of a digital file in architecture. This survey of Rome was translated into a numerical code, so that it could be sent with no loss or inaccuracy from one person to another, and redrawn accurately according to a set of instructions.

\begin{abstract}
'Alberti explains in a brief introduction how he had drawn the map, then "digitised" it using a system of polar coordinates. The rest of the book is in fact a list of numbers: the readers were expected to recreate the picture, identical or proportionally identical to the original, by feeding those numbers into a specific instrument, which Alberti also describes, and which today we would call a plotter. Apparently Alberti thought, with some reason, that this high-definition picture would better travel in space and time encapsulated in a digital file, and that the original map should be redrawn each time anew based exclusively on the numerical data-rerunning the program, so to speak, and not via the "analogue," manual copy of other preexisting copies of it.' Carpo 2011:54-55.
\end{abstract}

The copying enabled by tracing paper is insufficient, by this measure: as we shall see, it introduces variation and inaccuracy; crucially, this is the quality which makes it such a valuable part of the design process - not only does it introduce inaccuracy, but it allows it.

Recent work in fine art and anthropology have revived ideas of copying the work of acknowledged masters both as a way of learning about that work and about the act of drawing itself.

The discussion of art and creative practices has, problematically, often been restricted to the outcomes and product of creative practices: the art-object (such that categories of art are even valid in all cases). Influential works such as Gell's Art and Agency have compounded this with discussions of the social pressures which build up to the production of a work, but never the making itself.

The act of copying is relevant to a wide range of creative practices. By way of example, it is worth examining copying in two contrasting contexts: long-established calligraphy practices and within contemporary art practices respectively. The first of these is explored by anthropologist Fuyubi Nakamura, who writes on contemporary Japanese calligraphy practices (2007). This paper challenges the foundation of art and creative practice by the nebulous criterion of originality. The aura, so challenged in the aesthetic theory of Adorno and appreciated by Benjamin, appears to be alive and well in discussions of art, particularly from outside the actual practice of art. Nakamura instead locates both artistry and creativity as residing within skilled practice. This is not to exclude other forms of creativity, but rather to underline the possibilities of this form. Once again recalling the concepts of autographic and allographic works noted by Goodman, and further challenging the notion that these are fixed states. Perhaps such states are rather more fluid and contingent than might at first appear. 
The presence of the model in Japanese calligraphy is well established, but this is distinctive from absolute, perfect copying. In a manner akin to the pianist approaching a score, the calligrapher, through practice and training, becomes more and more competent to the point of virtuosity with regards to an originating model: surpassing it whilst still referring to it. Western art history is similarly littered with referential works. The ruptures of Modernism in art which emerge in the late 19th and early 20th century continue to draw upon their predecessors.

Nakamura problematises the idea of the copy, preferring to talk about reproduction with reference to Benjamin's essay on The Work of Art in the Age of its Mechanical Reproduction. In the reproductive practice, Nakamura contends, the aim is to understand more than what is on the paper:

Keirin: First stage, focusing on the mechanics of brush technique.

Irin: Second stage, interpreting the spirit and intention of the work.

Hairin: Third stage, reproduction from memory without looking at the model.

adapted from Nakamura, F. (2007: 82)

Some forms of inscriptive practice have more in common with musical performance, where the trace is the result of a set of gestures. Ingold (2007:72-75) contends that in many cases, the trace can be regarded as incidental, and that the trace is what is important.

Secondly, artist and researcher Patricia Cain examines copying in contemporary art practice. Cain discusses the idea as a re-enactment of a drawing in an experiential account of copying a drawing, Glass, by Richard Talbot (2010:134-143, 155-247). The account is told through text, journals, and stages of the drawing, a precise and complex pencil drawing comprised of elliptical planes cut through a bulb-shaped object in perspectival projection. Cain, after making an initial copy, in the Keirin stage, then moves towards what Nakamura identifies as Irin, where a series of further diagrams are produced to interrogate the intent and decision making process behind Talbot's originating work. Finally, the hairin stage is also engaged with, where Cain produces a series of Wall Drawings which interpret the engagement with Talbot's drawing, but by allowing a conversation to emerge with her own practice.

This account reveals many of the struggles, risks and uncertainties in producing a drawing as well as the possibility for understanding through copying, retracing, re-enacting, or using a work as inspiration.

\section{LAYERING}

Tracing as layering: Wigglesworth \& Till's Increasing Disorder in a Dining Table 2 is a rare example of an architectural drawing which is intended to show all of the accumulated positions occupied in the course of a meal. As a sequential drawing, it challenges the notion of the original state, the dining table as it might appear in a conventional architectural plan, pristine and with no traces of occupation or mess. By layering one set of positions over another, movement is suggested - but not accurately represented, as we do not know the rules or order in which we are expected to read the position of a single plate: what we have is an architectural plan which continues to behave as such: depicting the spatial extent of each object, its territory on the table. The series of three drawings was further developed into a diagram for a house, jagged overlapping forms reminiscent of time-and-motion studies.

Sequential tracing is commonplace in architecture, particularly in mechanical drawing and sketch practices. This predigital practice remains - and indeed has been adopted as a logic included within

2 Reproduced in Wigglesworth, S. 2009. "Body Works" in Deviant Decoration. Pennsylvania State University. http://www.swarch.co.uk/assets/Uploads/publicity/Deviant-deco-catalogue.pdf Accessed 15/11/16. p.22 
many CAD and other digital drawing packages. The example here is from the work of the British late modernist, James Stirling. I have focused in my recent research on the axonometric drawing, an under theorised form of architectural drawing which found a place in many 20th century architects' practices. This work is forthcoming in: Drawing Parallels: Knowledge production in axonometric, isometric, and oblique drawings (Lucas 2017b). This text examines the varying roles of this drawing convention as adopted by Stirling, Peter Eisenman, John Hejduk, JJP Oud, and Cedric Price.

Stirling's use displays astonishing virtuosity, with reverse-angle or worms eye views depicting circular and curved forms on both axes, around ramps, and using geometry which appears to be deliberately challenging to draw in this form of projection. It can be argued that the conventions of axonometric are used to give form to many of Stirling's works as a part of this process.

In this series of studies for the Latina public library project (unbuilt, 1983 CCA Stirling Fonds: AP140.S2.SS1.D67.P7.140-249), Stirling (with partner Michael Wilford) begins with a base drawing and copies it repeatedly, making changes to the treatment each time. This is the alteration possible and afforded by the translucent paper. Lines can be selected and given permanence through repetition, others are abandoned, corrected, altered. Tracing can also be a form of compositing, allowing elements to be gathered together from a variety of sources and placed into an overall composition; pieces contributing to a whole.

FIGURE 1: Redrawings of Latina Library Studies by the author.

FIGURE 2: Adaptation and reworking of Latina facade by 'Making Traces' workshop participant.

All of this language suggests editing, montage, and juxtaposition: all distinctively modern concepts, and ones which have been successfully theorised in cinema studies. The logic of composition in tracing, then, can be understood as a kind of modernist practice of emergent forms, experimentation and iterative design processes which crucially record all of the traces of that process. That architects prefer then to show a finished drawing is perhaps a convenient lie, one which erases the process by which it was arrived at: only the top sheet in a stack is shown to the client, the audience.

The stack is considered as simultaneously singular and multiple: the support has that thing paper is often assumed not to have: thickness rather than merely surface. Of course, surface, and the superficial is ripe for rehabilitation as a concept (see Lucas, 2017a in Anusas \& Simonetti (Eds.), forthcoming).

\section{TOLERANCE + PRECISION}

Tolerance is a concept discussed a great deal within architectural discourse, but rarely theorised. Tolerances are an aspect of materials in construction and the accuracy with which they can be measured and cut: bricks will have small variations despite their manufacture, and additional tolerances due to the action of the mortar which holds them together; different types of timber will have properties under structural stresses and weather conditions, with overlapping elements designed to accommodate the variations inherent in each piece of wood.

This notion of tolerance is also present - in a different form - in design drawings, where absolute measurement is not as crucial as it might first appear. In this sense, tolerance is the degree acceptable inaccuracy or variation where the drawing either employs a secondary numerical notation: tolerance acts as a system where measurements remain within certain limits, proportions are maintained, and the margin of error is a known value. This is essential to the communicative aspect of design drawings, where the architect eventually passes drawings to a third party for the purposes of actual construction. Additionally, the tolerances can be specified relative to the materials in question, for example timber cannot be cut as precisely as than steel, where a value of $+/$ - is applied to the line. 
A line can be accurate in ways other than the absolute translation of a scaled relationship to the projected reality: the notion of a self-correcting system is important here, where the constellation of lines together offer a consistent representation of reality. There is often a way of offering a registration point or scale reference which allows the drawing to maintain an internal consistency.

Tolerances in drawing are often left loose and open deliberately, as a design drawn where there is no room for error is difficult to construct as it is literally too exacting.

\section{CONVENTIONS}

Architectural drawings are most often drawn with reference to stable conventions. In this sense, a drawing convention can be understood a set of common understandings and rules which determine how a constellation of lines can refer to projected and existing forms. The clearest analogy would be a form of language consisting of symbols and arrangements which make sense when combined: a great many utterances are possible through any of the conventions of orthographic, parallel, and perspective projections.

The architectural theorist Robin Evans discusses these conventions as alternative projections in his work The Projective Cast: Architecture and its Three Geometries (2000).

Each of these conventions has a specific role in the design process. Plans are most familiar: top-down drawings resembling maps, where lines are true in both measured distance (usually to scale) and in angles (where a $90^{\circ}$ angle is represented as such). The plan is concerned with spatial relationships, the proportions of rooms and the circulation between them, describing thresholds and enclosures. Elevations, formal representations of facades, belong to the same family of orthographic drawings, and can be derived from the proportions and measurements of a plan. This would, in the mechanical drawing, be associated with tracing or multiple drawings on a single sheet, projecting lines from the plan to produce the measurements for the elevation. Elevations concern themselves with context and proportion most of all: placing the building into a setting to show how it responds to nearby structures, and showing the rhythm or harmony of the fenestration and surface detailing. Similarly structured to elevation drawings, cross-sections (most often simply referred to as sections) are a slice through the building, showing the thickness of walls and floors and the volumes they describe. The qualities of a space are made apparent by section drawings, and the decision about where to make the 'cut' are particularly important, showing the most interesting spaces and describing a sequence from exterior to interior. As a set of drawings according to a common convention, these drawings are often the product of tracing. (see Evans 1997)

Parallel projection works according to quite different rules, and sacrifices the 'truth' of some angles in order to represent three dimensions on the page at once. The deformation introduces some potential for misreading and misrepresenting in this kind of drawing. Whilst some versions such as oblique and isometric drawings are used elsewhere, architecture tends to use axonometric and planometric projection most, as the ground plane is maintained in terms of its angles and proportions, essentially angling a regular plan drawing and projecting the walls up from this: the angle between the floor and a wall is deformed in this process. Overall compositions in 3 dimensional space are well described by parallel projection conventions, however, as they are able to convey an impression of form very efficiently and again can be based upon a tracing of the plan. (refs)

The final convention common to architecture is perspective drawing. Relegated to a presentational practice by most, it nonetheless remains a geometrically consistent system which does allow for some measurement and proportion to be expressed. A single viewpoint is represented in a perspective, of course, leading some to produce sequential practices (see Cullen, 1961), and most to use them as a final presentational tool: an enchantment of the potential client (e.g. Gell 2006; Ferriss, 1986).

Conventions are a form of social contract, allowing drawings to travel and be understood by similarly trained professionals across the built environment disciplines and across the world. This is the basis for 
much early scholarship in architecture from the Grand Tour through to the development of the profession in the 19th and 20th Centuries (Barnett Johnson 2008, Brothers 2008)

\section{ECCENTRICITY}

The presence of conventions does not, of course, preclude variations or eccentricities. Many architects have developed highly idiosyncratic responses to the norm when it comes to drawing, and such practices are deeply embedded within their design practices.

One example would be Junya Ishigami (2008) whose drawing practice uses tracing implicitly in an interesting manner, working with photographs of drawings overlaid with delicate coloured line work. Here, the tracing or transparency is used in a layering operation not to replicate the lines of a model or drawing, but to supplement it, adding people, vegetation, and other signs of life. Can such practices (which have a tradition stretching through the 20th Century with photo montage work by such varied architects as Mies van der Rohe (in Shields 2013), Lebbeus Woods (2001), and Archigram (Cook \& Webb 1999). Where the logic of montage in film might be as a horizontal unfurling of images where the point of montage represents a temporal or spatial rupture (Eisenstein, 2000), we can see in the photomontages of architects a vertical arrangement of transparent coexistent layers. This is prefigured in Eisenstein's wonderful essay Vertical Montage (see Lucas 2006:83-95, 234-239 for more on this) in which he picks through the various layers comprising a scene in a film. Notably, another architectural eccentricity emerges from this: directly referenced in the early work of Bernard Tschumi (1996) and to a more oblique extent Daniel Libeskind.

Tracing remains an element of the discipline here, and architectural collage (Shields, 2013:63-127) can be understood as a form of traced assemblage, borrowing the logic of the familiar practice and re-presenting it in layered multimedia and layered drawings.

The density of Libeskind's 1979 drawing series Micromegas (see Scheer, 2014:84-99)and other drawings are testament to this, with the vast accumulation of decontextualised details inviting the viewer to lose themselves to the drawing, finding emergent conditions from within the whirl of details and fragments, like a cubist painting assembled out of architectural elements. This series of drawings (hosted on the architect's website ${ }^{3}$ ) invites the viewer into a simulation of the process of finding and selecting lines from a deep stack of layers.

Relating back to a convention prevents such drawings from remaining purely abstract, arbitrary, or wilful. Instead, they have a reference point from which they might diverge, but those divergences are informed decisions, each time telling the viewer something through the distance introduced.

\section{PLURALITY OF PAPER}

The practices of greatest interest in this account of tracing are the stacks of tracing paper taped or pinned to a mechanical drawing board, representing the dominant mode of architectural design during the majority of the 20th Century, falling between the professionalisation of the discipline, surviving the emergence of modernism, and persisting in an altered form once digital drawing becomes the norm. This practice is a case study which allows us to explore the concept of tracing and its broadest implications in the round, and is an activity which is relatively under-represented by the literature on drawing.

It is important to discuss paper as potentially plural, that a drawing might be a bundle of papers together, singular and plural simultaneously (discussed in detail by Lois Olcott Price, 2010:76-81). This is conceptually distinctive from the way many other practices of drawing might be considered, the discussion of

${ }^{3}$ http://libeskind.com/work/micromegas/ 
sketches as preparatory works for paintings or more 'finished' drawings, or the iterative practices of repeating an action until it is satisfactory being good examples. It is both useful and important to consider the possibility of a single drawing existing on many layers of paper. Olcott Price notes that tracing paper was used not only in the drawing process, but also in the reading of drawings (2010:76), particularly of mechanical devices with multiple interacting systems. Drawn separately, individual systems could be isolated and viewed through the use of tracing paper.

By way of case study, it is worth examining a sheet of drawings by James Stirling of the unbuilt Bibliotecca Publica in Latina (CCA Stirling Fonds: AP140.S2.SS1.D67.P7.1-51). The sheet contains a series of studies for one facade of the building, running through variations in the treatment of a projection from the gable end of the building. A range of responses are given, from balcony projections of asymmetrical prisms to undulating wave forms. Several sheets from the scheme are held in the collections at the Canadian Centre for Architecture, some of which reveal the process of drawing over earlier sheets in order to produce variations.

It is instructive to take this task on oneself.

Take a print of the gable end of the library and place it on a drawing surface, securing it with tape. Place tracing paper over the top of this sheet and draw the outline of the gable, projecting back to give it 3-dimensional form, but leaving the projecting balcony off for now.

Produce a variation on the projection and repeat.

After producing a good number, compare these to one another and select the most appropriate design response.

The experience of handling materials in this way is strange to non-architects, and material frustrations are part of the process: holding the paper taut enough so that it remains transparent, seeing through several layers of paper can become challenging to an unaccustomed eye, and errors in the base drawing may replicate and become sedimented within the drawing.

The question of whether to take sheets of mid-drawing is an interesting one, and represents a return to a ur-condition each time rather than developing the design.

\section{EDITING + SELECTING}

Whilst working with layers of paper, a series of decisions are enforced on the designer. This selection and discernment is a crucial element of the iterative design process where initial ideas are tested against a series of principles and requirements, most often consolidated in a brief provided by a client and refined by the designer. Interestingly, a number of contemporary architects consider the briefing document to be one of the elements of the design process rather than an external force upon it. Bernard Tschumi develops this in his texts Architecture and Disjunction and Event Cities series of books (1994, 1996), where the programme it tested for its creative potential and opportunities.

This iterative design process is variously imagined as a double diamond process of widening out and narrowing; or of looping repeatedly until a design passes judgement and critique. Through this, however, a design process is one which has memory: the very first concepts, in the folk wisdom of the studio, are often the best: but due diligence and demands of the brief often require the designer to play through a number of other options.

Much of this will happen in sketchbooks before committing to the layered transparency of tracing paper or its digital successors, but once in a tracing mode of design, this immediate history of the process becomes more accessible. This is one of the areas in which architecture borrows the idea of the palimpsest, (Huyssens, 2003; Bork, 2011:42-51; Machado 1976) used colloquially to describe both site conditions and pre-existing architecture or urban form, but also the process of working with layers of drawings and finding a way through them towards a design resolution. 
Several kinds of lines are produced when working with tracing paper. Construction lines are used as measurement, often proportioning the page itself, and aligning one sheet of drawings with another as a broad set of proportions and measurements. The design itself is then 'pencilled in' so that it can be erased and reworked more easily. Working drawings and finalised versions are rarely produced at this stage, with a fresh sheet started and the desired lines selected for inking. The commitment represented by the ink line as opposed to pencil is an important distinction. In practical terms, it is very difficult to rework a stray ink line, to the extent that the best option is carefully scratching the ink from the surface with a sharp scalpel, taking advantage of the non-porous nature of the paper. This gradually weakens the paper, of course, and is a measure of last resort given the further processes of printing which a final drawing will undergo for reproduction. A robust and cleanly executed artefact is important.

The craft that goes in to the drawing is often neglected, and the quality of the inscribing gestures is quite different from one process to the next: the sketch is looser, but often drawn quite small: the cliche of the 'thumbnail' sketch; the pencil lines are ruled using T-square and parallel motion, and can be quite swift \& bold whilst constrained by mechanical tools; finally the inked lines have a combination of hesitancy and directness. Hesitant as this is a risky activity: a single mistake could mean starting afresh no matter where in the process one is, but the lines must have a directness to them, otherwise the ink will pool and gather, the line will have a shaky quality. The directness is aided by having clear guidance from the layers below, but the ink drawing is a fraught activity.

The status of the different lines in tracing processes are interesting to consider, distinguished by their intentions more than any discernible graphic quality of the marks. The 'final' drawing is most often considered as the drawing to the detriment of the stack of paper it takes to arrive there. This renders the drawing as a kind of image rather than the trace of gestures, as the persistent result of a series of practices. Whilst this is pragmatic in the use of such drawings, when it comes to the academic understanding of creative practice, this attitude is reductive. The visible lines of the final drawing (perhaps final only in the sense that it is the uppermost sheet of paper in a stack) are not the only important ones, and the invisible lines such as the pencil work, variations on themes, and even construction \& proportioning lines ought to be considered as important. To edit these out of the academic and public reception of drawing is to create an aura of enchantment (to cite Gell (2006) on the technology of enchantment once again) which excludes the viewer, implicitly saying they barely have the expertise to read this drawing much less produce it.

\section{CONCLUSIONS: THE DISCIPLINE OF TRACING}

In fine art discourse around drawing, the paper is often referred to as the support for the medium' in the case of tracing paper, a series of interesting nuances are introduced. The first such complication is that, as a support, tracing paper is not stable. The lack of opacity demands certain material practices are followed. One such consideration is the surface tension of the paper. In order to maximise the degree of transparency, revealing layers below, tracing paper must be pulled taut on a drawing board, held in place by tape, pins, or clamps. When tracing, one might draw from layers other than the immediately preceding ones: two, three, or more layers might be visible depending on the degree of transparency offered by the paper and the keenness of the draughtperson's eye. The multiplicity of the drawing act allows a conceptual moving between layers, back and forth rather than a straightforward progress from $A$ to $B$ to $C$ and on. This allows the drawing to revive abandoned ideas which might come into use or relevance once other decisions have been made.

Fixing some lines over others, giving them a degree of persistence, can be achieved through different grades of graphite (choosing a lead of heavier weight such as 4B rather than the lighter, but more precise $4 \mathrm{H}$ ), or by selectively inking some lines. This makes some lines appear more permanent, more decisive. Such activities edit the lines available, making the choices of the draughtperson apparent. Somewhat akin to marginalia or notes to oneself, these are ways of communicating with oneself during a design process, not intended for external consumption. 
The referent for the drawing becomes internal to the process, where drawings follow from one another rather than directly from the context or the client's brief. This internalisation of the architectural referent was explored thoroughly in the early work of architects such as Peter Eisenman, who sought to establish a purely architectonic expression without recourse to natural metaphors or repetition of classical styles. Distilling the purely formal characteristics from canonical architecture (ref), Eisenman, along with his contemporaries and students, developed architectures which were in many ways entirely and deliberately formal. (Ref fin'd out h'ouse, etc.)

Often, this tracing practice relies upon stable drawing conventions such as orthographic plan, section, elevation; or parallel projections such as axonometric or isometric. Less common are stacks of tracing which depict perspective, although this can be used effectively as it represents a geometric understanding of space. What we do not see, however, are loose informal sketches without a driving geometry: the convention is crucial to how tracing works as a drawing practice.

This chapter begins with the idea of the discipline of tracing in architectural drawing, and it is here that it must reach for some conclusions. A great deal of work has been done in anthropology regarding human movement in a variety of contexts which could be broadly grouped together as forms of dance. The theory emerging from this, of embodiment and embodied knowledge approach to drawing in some fruitful ways. Central to this is the work of Maxine Sheets-Johnstone (1999), Drid Williams (1999), and Brenda Farnell (2012).

Writing on the process of design in the Beaux-Arts, Hyungmin Pai describes the process and intention of tracing:

'Drawing had always been a crucial part of the academic discipline, and indication was not merely a static method of redrawing but a mechanism of altering and transforming....... In other words, indication was not merely a drawing technique but a process of seeing, reading, and drawing that underlay the Beaux-Arts logic of architectural creativity. The term itself contains the sense of drawing as an act of revealing something that is hidden, something that is not immediately visible. An effective drawing revealed is basic idea-the parti-while simultaneously facilitating the further development of sections, elevations, and details. Placing a tracing paper over a plate and following the lines of the underlying plan was not merely copying, or in Beaux-Arts slang, "cribbing"; rather it was an act of searching for the many lines already encrusted in the drawing.' (Pai, H. 2002:46-47)

Of course, this can be extended not only to searching for the many lines encrusted in a source drawing from the accepted canon of architectural history, but also in order to extract further meaning from one's own drawings. Pai later makes in intriguing distinction between these lines-drawn from canonand those considered to be diagrams. The category of diagram in this sense is the 'delineation of a set of standard dimensions' (2002:252), such as the examples of bathroom fittings in a graphic standards manual. Tracing and copying these lines is not the same as copying an architectural drawing: there are no hidden depths to the diagram, no encrustations of meaning to be scraped away.

'Like the notational system of music, architectural representation was not a mere repetition of identical performances. Each performance of a typical score adds to the abstract "thickness" of the notations. The design process was therefore a search within and over these dense traces, reading into and drawing out architectural ideas.' (Pai 2002:54)

This 'hermeneutics of transcription' (2002:54) describes an architectural design process where tracing paper is not only useful, but is material to it: transparency, copying, repeating and varying are all afforded by transparent papers, being such crucial parts of the profession's design process that contemporary digital process replicate and build upon this method, from the layers present in illustration and CAD packages through to the iterative transformation of parametric design. 
Tracing constitutes a form of knowledge production within architecture, one with remarkable persistence given the significant changes in dominant modes of architectural production in the past two decades. Tracing offers opportunities for both copying and novelty through the selection and omission of lines, introduction of variation and intervention. This is achieved through the layering of paper: establishing a logic where the grounds of the drawing are not singular, but plural: there is an instability to this support, layers can be re-ordered, old traces revived, and redeployed. The key features of what can be said to be a discipline of tracing lie in this plurality of paper. As a material, the stack of paper can be manipulated, searched through, and re-ordered: representing a totality of the thinking process around a design.

It is worth reiterating the distinction here between tracing and trace: that the trace represents a connection between gesture and mark, with the trace as a persistent record of that movement. Tracing represents a series of possibilities and potentialities which are themselves constructed from traces. One of the most exciting elements of working with a stack of tracing paper is that it remains so full of potential: some options are not pursued where others are taken to a conclusion. There are continuities and discontinuities, flows and abrupt halting. There is a depth and thickness to the tracing paper drawing: rendering the paper as a medium in the manner of Gibson's (1986:22, see also Lucas, 2012 \& 2017a) tripartite distinction between surface, substance, and medium.

Tracing paper and its attendant practices has left its mark on architecture as a discipline, such that tracing represents a disciplining activity within the practice of architecture. Drawing is a catch-all term for a wide range of practices, with much of the literature devoted to a vague notion of representational sketch-perspective drawing to the neglect of a great many other practices. By examining the materials and the practices of their use, a greater understanding of drawing and inscriptive practices more broadly will be the result, and with this, a greater insight into how drawing is a scaffold for thinking when designing.

\section{ACKNOWLEDGEMENTS:}

This paper is based on research supported by the European Research Council Advanced Grant 'Knowing from the Inside' led by Tim Ingold (project no. 323677). The author is an external advisor and associate researcher on the project.

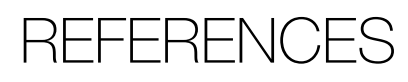

Anderson, S. 1984. "Architectural Design as a System of Research Programs", in Hays, K. M. (Ed.). 2000. Architecture Theory Since 1968. pp.492-505

Barnett Johnston, G. 2008. Drafting Culture: a Social History of Architectural Graphic Standards. Cambridge, Massachusetts: MIT Press.

Bork, R. 2011. The Geometry of Creation: Architectural Drawing and the Dynamics of Gothic Design. Farnham: Ashgate.

Brothers, C. 2008. Michelangelo, Drawing, and the Invention of Architecture. New Haven: Yale University Press.

Cain, P., (2010), Drawing: the Enactive Evolution of the Practitioner. Bristol: Intellect Books.

Carpo, M. 2011. The Alphabet and the Algorithm. Cambridge, Massachusetts: MIT Press.

Cennini, C. D'A. 1960 [c.1400]. The Craftsman's Handbook. D. V. Thompson, Jr. (Trans.). New York: Dover.

Cook, P., Webb, M.. 1999. Archigram. Princeton Architectural Press. 
Cullen, G. 1961. The Concise Townscape. Oxford: The Architectural Press.

Eisenstein, S. (2000), "How I Learned to Draw (A Chapter About my Drawing Lessons)" in De Zegher, Catherine (Ed.). Drawing Papers 4: The Body of the Line: Eisenstein's Drawings. New York: The Drawing Center.

Evans, R. 1997. "The Developed Surface: an Enquiry into the Brief Life of an Eighteenth-Century Drawing Technique" in Translations from Drawing to Building and Other Essays. London: Architectural Association. pp.195-231.

2000. The Projective Cast: Architecture and its Three Geometries. Cambridge, Massachusetts: MIT Press.

Farnell, B. 2012. Dynamic Embodiment for Social Theory: I Move Therefore I Am. London: Routledge.

Ferriss, H. 1986 [1929]. The Metropolis of To-Morrow. New York: Princeton Architectural Press.

Flusser, V. 2014. Gestures. Minneapolis: University of Minnesota Press.

Gell, A., (1998) Art and Agency: an Anthropological Theory. Oxford: Oxford University Press.

- 2006. "The Technology of Enchantment and the Enchantment of Technology" in The Art of Anthropology: Essays and Diagrams, pp. 159-186. Oxford: Berg.

Gibson, J.J. 1986. The Ecological Approach to Visual Perception. Psychology Press.

Goodman, N. 1976. Languages of Art. Hackett Publishing Co..

Huyssens, A. 2003. Present Pasts: Urban Palimpsests and the Politics of Memory. Stanford: Stanford University Press.

Ishigami, J. 2008. Small Images. Tokyo: Inax.

Lakatos, I. 1978. The Methodology of Scientific Research Programmes. Cambridge: Cambridge University Press.

Libeskind, D. 1979. Micromegas. Retrieved from http://libeskind.com/work/micromegas/ (accessed 5/8/2016).

Lucas, R. 2006. Towards a Theory of Notation as a Thinking Tool. Unpublished PhD Thesis. Aberdeen: University of Aberdeen.

Lucas, R. 2012. "The Instrumentality of Gibson's Medium as an Alternative to Space" in CLCWeb Special Issue: Narrativity and the Perception/Conception of Landscape. Purdue University Press. http://docs.lib.purdue.edu/clcweb/vol14/iss3/5/.

Lucas, R. 2014. "Towards a Theoretical Basis for Anthropological People-Environment Studies." in Edgerton, E., Thwaites, K., \& Romice, O. (Eds.). Advances in People-Environment Studies: Human Experience in the Natural and Built Environment. Göttingen: Hogrefe Publishing.

2017a. "Threshold as Social Surface: The Architecture of South Korean Urban Marketplaces" in Anusas, M. \& Simonetti, C. (Eds.). On surfaces: Contributions from Anthropology, Archaeology, Art and Architecture. London: Routledge (forthcoming). 
2017b. Drawing Parallels: Knowledge production in axonometric, isometric, and oblique drawings. Ashgate (forthcoming).

Machado, Rodolfo, 1976. "Old Buildings as Palimpsest" from Progressive Architecture. 57 (11) pp. 46- 49, Stamford: Reinhold Publishing.

Nakamura, F., (2007), "Creating or Performing Words: Observations on Contemporary Japanese Calligraphy” in Hallam, E. \& Ingold, T. (Eds.). Creativity and Cultural Improvisation. Oxford: Berg.

Olcott Price, L. 2010. Line, Shade and Shadow: the Fabrication and Preservation of Architectural Drawings. Houten: Hes \& De Graaf Publishers.

Pai, H. (2002), The Portfolio and the Diagram, Cambridge, Massachusetts: MIT Press.

Pallasmaa, J. 2009. The Thinking Hand. Oxford: John Wiley \& Sons.

Scheer, D. R. 2014. The Death of Drawing: Architecture in the Age of Simulation. London: Routledge.

Sheets-Johnstone, M., (1999), The Primacy of Movement. Amsterdam \& Philadelphia: John Benjamin's Publishing Company.

Shields, J.A.E. 2013. Collage and Architecture. London: Routledge.

Stoichita, Victor. 1997. A Short History of the Shadow. London: Reaktion Books.

Tschumi, B. 1994. Event Cities. Cambridge, Massachusetts: MIT Press.

1996. Architecture and Disjunction. Cambridge, Massachusetts: MIT Press.

Wigglesworth, S. 2009. "Body Works", Deviant Decoration. Pennsylvania State University. http:// www.swarch.co.uk/assets/Uploads/publicity/Deviant-deco-catalogue.pdf Accessed 15/11/16.

Williams, D. 1999. "Messages, meaning and the moving body", Visual Anthropology, Vol. 12:1, pp. 87-97. Taylor and Francis.

Woods, L. 2001. Radical Reconstruction. New York: Princeton Architectural Press. 